\title{
Effect of Compression Refining on Fiber Properties
}

\author{
Jari Käyhkö, ${ }^{\text {a,* }}$ Eero Hiltunen, ${ }^{\mathrm{b}}$ Yrjö Hiltunen, ${ }^{\mathrm{a}}$ Ekaterina Nikolskaya, ${ }^{\mathrm{a}}$ Lauri Kulmala, ${ }^{\mathrm{a}}$ \\ and Thaddeus Maloney ${ }^{\mathrm{b}}$
}

\begin{abstract}
This article shows how fiber properties obtained by the compression refining of bleached softwood pulp refined using a KID 300 refiner differs from traditional bar refining. A KID refiner is a stone crusher that has been modified to refine fiber, and it offers a refining method that could be used at the mill scale. This study showed that compression refining caused more internal fibrillation compared with blade refining and improved the pulp's ability to be beaten. Net energy consumption in compression refining was less than that of bar refining. Compression refining yielded pulp with shorter fibers and a higher number of fines, kinks, and curves. Still, the strength properties of the paper were the same level as barrefined pulp, probably due to the higher internal fibrillation and flexibility of the fibers. It was also shown that the low field time-domain nuclear magnetic resonance (TD-NMR) method was capable of measuring the porosity and internal fibrillation of the fiber.
\end{abstract}

Keywords: Compression refining; Fiber properties; Internal fibrillation; Pore structure; Time-Domain $N M R$

Contact Information: a: Fiber Laboratory, South-Eastern Finland University of Applied Sciences, Savonlinna, Finland; b: Aalto University, Espoo, Finland; *Corresponding author: jari.kayhko@xamk.fi

\section{INTRODUCTION}

Compression refining has been previously studied and it has been shown that it brings some advantages compared with traditional bar refining. The main difference compared with bar refining is that compression refining produces mainly internal fibrillation, which is thought to be one of the most important targets in refining (Hartman 1984; Tam Doo and Kerekes 1989; Dunford and Wild 2002; Wang et al. 2006; Dekker et al. 2007; Goosen et al. 2007). In addition, the use of compression refining could enable a more homogeneous refining treatment. Bar refining is known to be heterogeneous, and it is even possible that a large portion of the fibers do not receive any refining treatment at all when it is employed (Dekker et al. 2007). Despite extensive studies, compression refining has not reached the commercial level. Many devices have been developed that more or less produce compression-type refining, such as the Lampen mill (Kibblewhite 1974; Wang and Paulapuro 2005), the PFI mill (Murphy 1962; Formento et al. 2003; Eibinger et al. 2005a, 2005b), and pilot PFI (Dekker et al. 2007), but these techniques have been difficult or impossible to scale up.

One interesting option for achieving compressive refining on an industrial scale is the employment of a variation of the stone crushers produced by the Russian company Mekhanobar Technica. Based on that technology, a device - the KID refiner-that is suitable for the compression refining of wood fibers, has been constructed. This technique is of interest because it could be used on the mill scale. In this study, the KID compression refiner was compared with a traditional plate/bar refiner. The main objective was to show 
how the refining result differed in bar and compression refining and the possible technical benefits of compression refining.

\section{EXPERIMENTAL}

\section{Pulps}

Never-dried, bleached softwood pulp of medium consistency was obtained from a sulphate pulp mill located in southeastern Finland.

\section{Refining Test Procedures}

Compression refining was performed using a modified KID refiner (KID 300; Mekhanobr Tekhnika, St. Petersburg, Russia) (Fig. 1). The refining action was based on a rotating eccentric axle that was placed inside the freely flowing center part of the refiner. There is bearing between axle and center part, and hence when the axle is rotating the center part is not rotating. The rotating axle makes the center part vibrate against the outer wall of the refiner so that if there is no pulp in the refiner the center part hits against the outer wall. The center was flowing freely, and hence the speed difference between the center part and outer wall was zero. This meant that KID refining created only compressive forces. The pulp flowed through the refining zone with the aid of gravity and vibrating action. Refining conditions had a consistency of $5.5 \%$, frequency of $60 \mathrm{~Hz}$, medium distance between inner and outer wall of $4.5 \mathrm{~mm}$, width of the refining zone of $100 \mathrm{~mm}$, production of $0.14 \mathrm{t} / \mathrm{h}$, and net energy consumption in one refining cycle of $5 \mathrm{kWh} / \mathrm{t}$. From these values it was calculated that fibers received approximately 100 compressing hits in one refining cycle. The actual number of hits was less because most likely a movement caused the fibers to escape from the compressing zone (i.e., the grammage of the fiber mat under compression was actually lower than calculated). The KID refining was performed by circulating pulp through the refiner between three and twelve times.

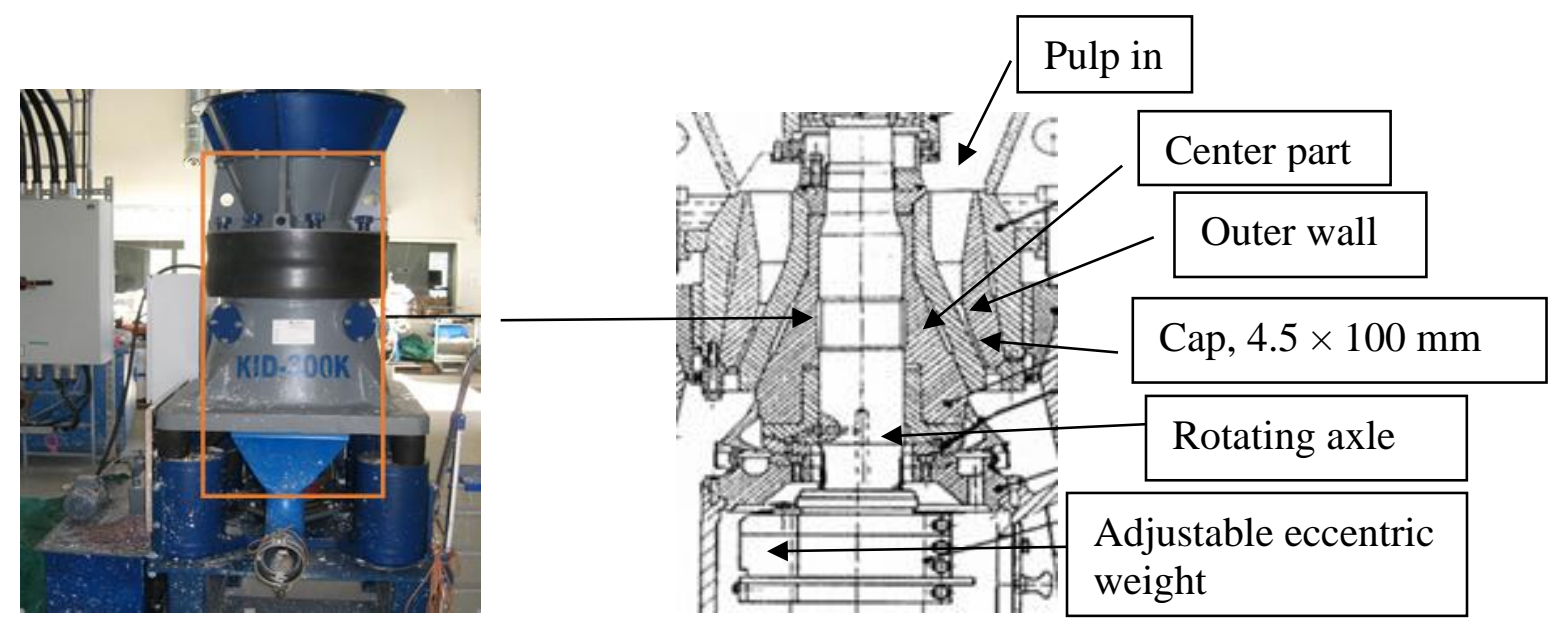

Fig. 1. The KID-300 compression refiner; the label 300 refers to the $300-\mathrm{mm}$ diameter of the refining zone

The bar refining was performed using an Andritz (Karhula, Finland) single disc pilot refiner (Fig. 2) by circulating pulp through the refiner between three and ten times. The diameter of the refining plate was 25 in, consistency was $2 \%$, production was $0.3 \mathrm{t} / \mathrm{h}$, 
rotational speed was $1500 \mathrm{rpm}$, and the net energy consumption in one refining was 45 $\mathrm{kWh} / \mathrm{t}$ and SEL $1.0 \mathrm{~J} / \mathrm{m}$. Laboratory refining was completed using a Valley Hollander (AB Loretzen \& Wettre, Stocholm, Sweden) according to the SCAN-C 25 (1976) standard.

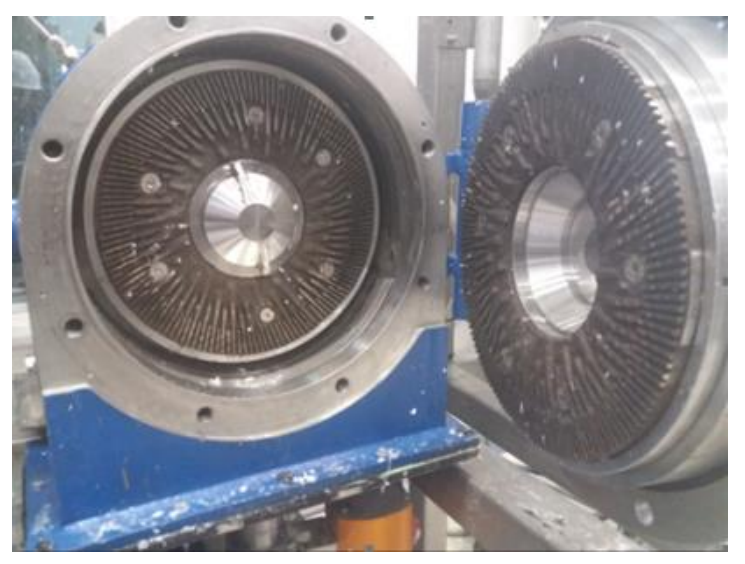

Fig. 2. Andritz pilot-scale disc refiner used in these studies

\section{Measurements} follows:

The measurements and their descriptions that were used in this study are as

- The ${ }^{\circ}$ SR measurements were carried out according to the ISO 5267-1 (1999) standard.

- Fiber properties were measured using a Metso Kajaani Fiber Tester FS 300/FS5 (Kajaani, Finland). The measurement principle of the tester is based on the optical micrography

- Low Field Nuclear magnetic resonance (NMR) measurements were made using a modified TD (time domain)-NMR analyzer (Resonance Systems, Savonlinna, Finland) with a ${ }^{1} \mathrm{H}$ resonance frequency of $21.70 \mathrm{MHz}$. The inner diameter of the NMR probe was $19 \mathrm{~mm}$. The NMR signals were measured using a Carr-Purcell-Meiboom-Gill (CPMG) pulse sequence, and spin-spin relaxation rates $\left(R_{2}\right)$ were determined. The measurement was made $25{ }^{\circ} \mathrm{C}$ at $5.5 \%$ consistency for KID-refined samples and in 2 $\%$ consistency for plate refined samples.

- Fiber pore measurements were made using the solute exclusion test originally developed by Stone and Scallan (1968) and modified by Maloney (2000). In the solute exclusion test, the water inaccessible to a probe dextran molecule was measured. If the dextran polymer was large enough that it did not enter the cell wall, then the fiber saturation point (FSP), a measure of overall fiber swelling, was measured. If smaller dextrans, capable of partially diffusing into the cell wall, were used, then further information on the cell wall pore structure was obtained. The FSP was measured using a $2 \times 10^{6}$ Dalton dextran with a Stokes diameter of $54 \mathrm{~nm}$. The second probe molecule was a $5 \times 10^{3}$ Dalton dextran with a diameter of $3.2 \mathrm{~nm}$. This was used to measure the volume of small pores, referred to as "micropores." The difference between the FSP and micropore volume equaled the volume of mesopores in the cell wall.

- The water retention value (WRV) was measured according to the standard ISO 23714 (2014).

- Microscopy imaging was performed using an Olympus BX5 microscope (Olympus Corporation, Tokyo, Japan) with a magnification of 200. 
- Laboratory sheets were created according to the standards ISO 5269-1 (2005) and SCAN-CM26 (1999).

- Tensile and tear index were measured according to the standards ISO 5270 (2012), ISO 1974 (2012), and ISO 1924-2 (2008).

\section{RESULTS AND DISCUSSION}

\section{Fiber Properties}

Figure 3 shows microscopic images from the unrefined and refined fibers. A clear difference can be seen in how KID refining and bar refining treated the fibers. With bar refining, the fibers appear to have remained intact, but with KID refining, the fibers appear to have received very strong treatment.

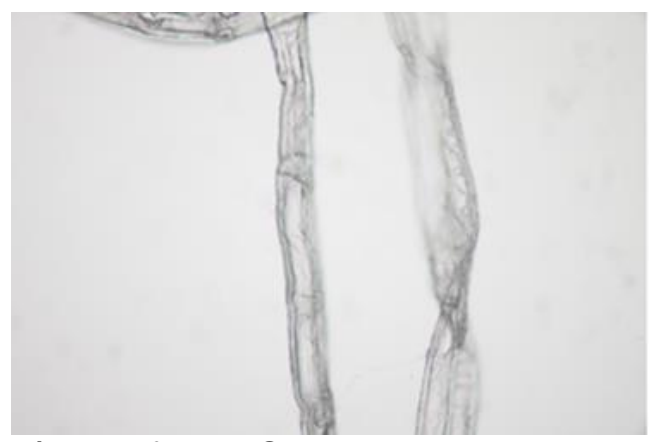

A) Unrefined, ${ }^{\circ} \mathrm{SR} 12$

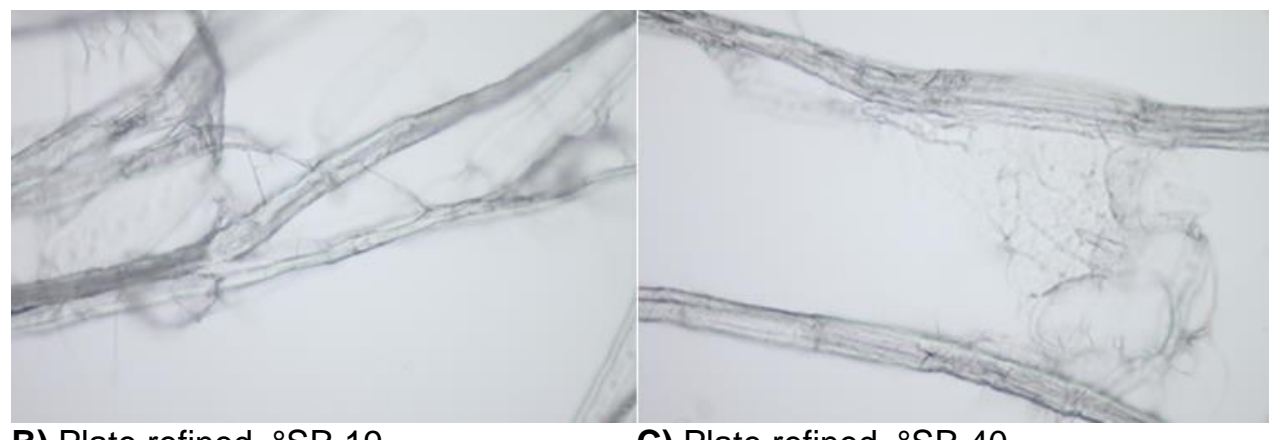

B) Plate refined, ${ }^{\circ} \mathrm{SR} 19$

C) Plate refined, ${ }^{\circ} \mathrm{SR} 40$

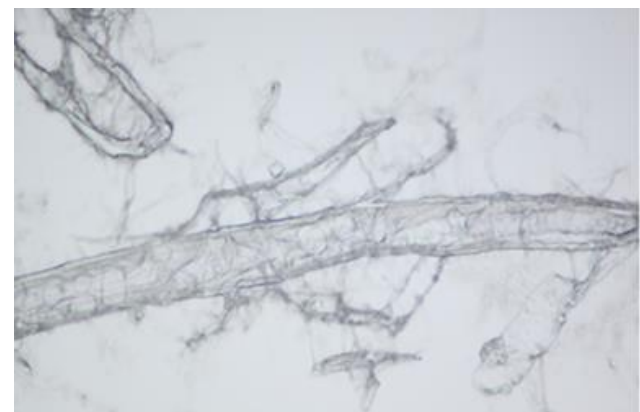

D) KID refined, ${ }^{\circ} \mathrm{SR} 25$

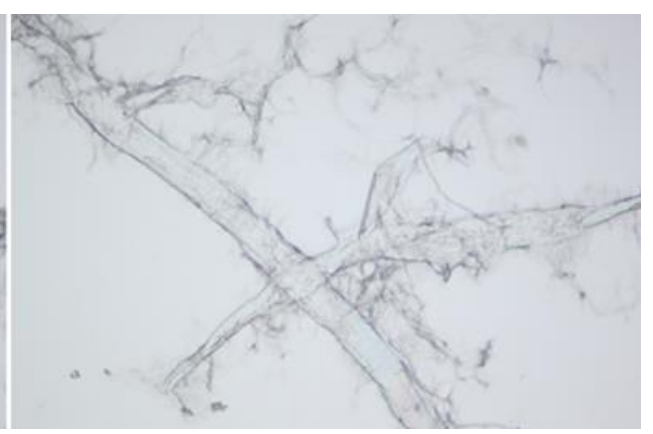

E) KID refined, ${ }^{\circ} \mathrm{SR} 30$

Fig. 3. Microscopic images from the unrefined and refined fibers 
The differences in the results obtained from these refining methods could also be seen clearly in their properties measured with the fiber analyzer (Fig. 4). With KID refining, the fiber length became shorter (Fig. 4a) and the formation of fines was stronger (Fig. 4b). The kink and curl values (Figs. 4c and 4d) remained higher with KID refining, which showed that this refining method did not apply enough force to straighten the fibers as compared with bar refining. These results indicate that in the KID refining, fibers obtain much higher compressive and lower shear forces compared to the plate refining. Although fines content in the KID refining increase strongly, this does not have big impact on the ${ }^{\circ} \mathrm{SR}$ number (Fig. 4 b). This indicate that fines formed in the KID refining are mainly flakelike non-fibrillated material. Microscopic images in Fig. 3 also support this assumption.

It is of interest that KID refining did not decrease fiber width in the way that bar refining did (Fig. 6a), despite the fact that KID refining did erode the cell walls and generate more fines than plate refining did (Fig. $4 \mathrm{~b}$ and Fig. 4e). This result was probably because KID refining was more efficient at swelling fibers than plate refining.

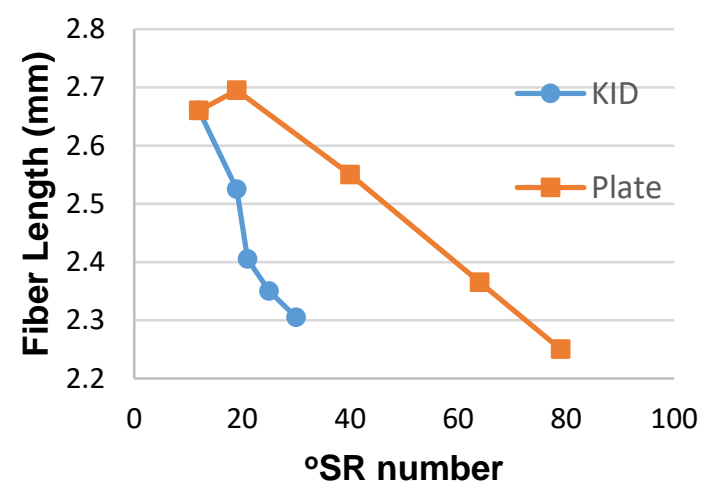

A) Fiber length (weight weighted)

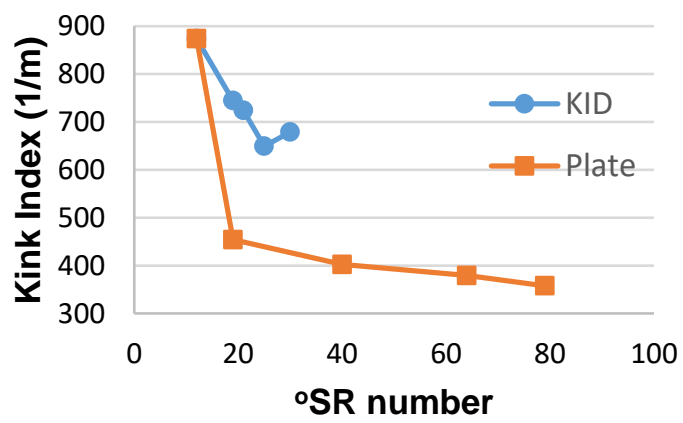

C) Kink index

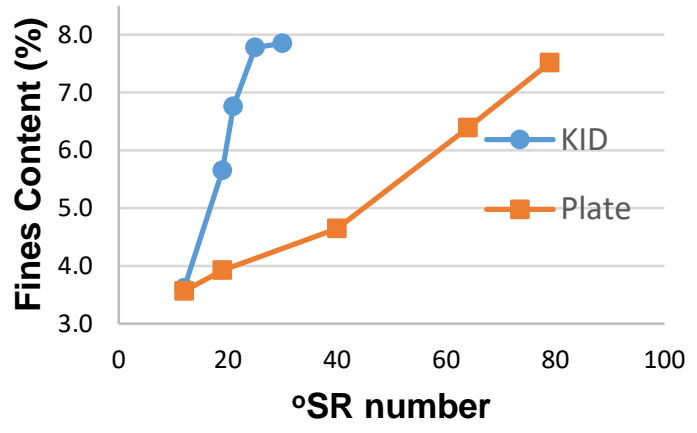

B) Fines content (length weighted)

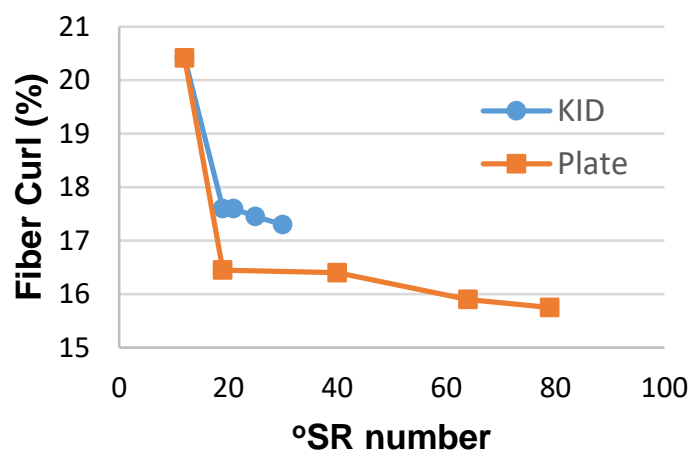

D) Fiber Curl 


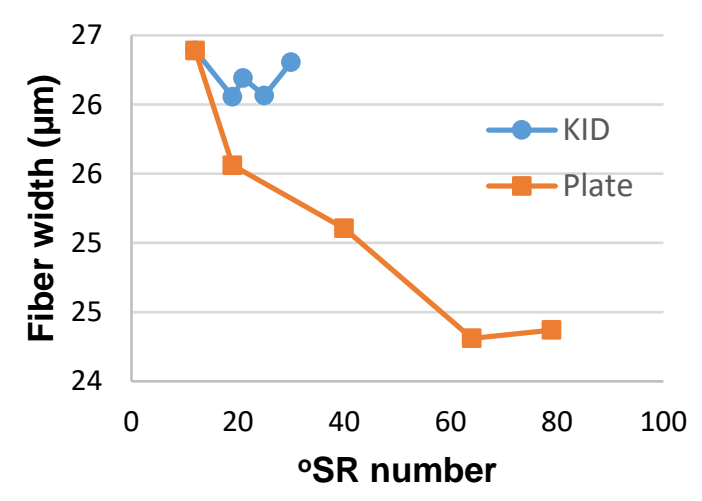

E) Fiber width

Fig. 4. Effect of the refining method on the properties measured with the fiber analyzer

Three other parameters that are closely related to the internal fibrillation of fibers were also measured. Water retention value is a simple and precise centrifuge test that can measure fiber swelling. It is often used in research and mill settings for practical reasons. The WRV depends on the internal fibrillation, external fibrillation, and fines properties, and thus provides practical information of interest. For instance, WRV correlates inversely with press dewatering. Figure 5 shows that the WRV increased with the refining extent, measured with ${ }^{\circ} \mathrm{SR}$, but that it did not show any difference between the refiners. However, when swelling was measured with the FSP (Fig. 6a), a clear difference between the refiners was noted. As this study already showed, KID refining appeared to more effectively swell the fibers than bar refining did. The WRV can give misleading information for highly swollen pulps. As swelling increases, the modulus of the cell wall decreases, causing the pulps to become easily compressed and dewatered in the high centrifugal field of the WRV test. Then, highly swollen pulps can give WRVs that are too low when compared with their actual swelling. Solute exclusion does not suffer from this problem, and thus is a more accurate representation of the differences between the KID and plate/bar refiners with respect to internal fibrillation ability (Maloney 2000). The NMR technique (Fig. 6b) showed a clear increase in the relaxation rate $\left(R_{2}\right)$ value of the KID-refined pulps compared with the bar-refined pulps. This was consistent with the high FSP discussed above. 


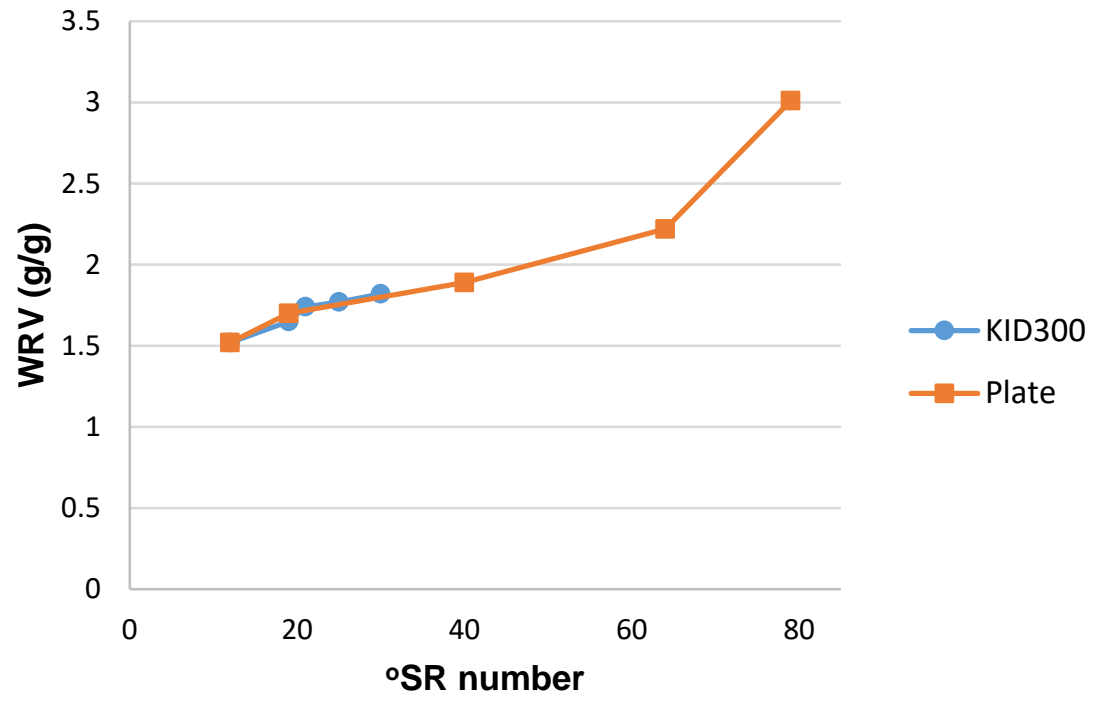

Fig. 5. The effect of the refining method on the WRV

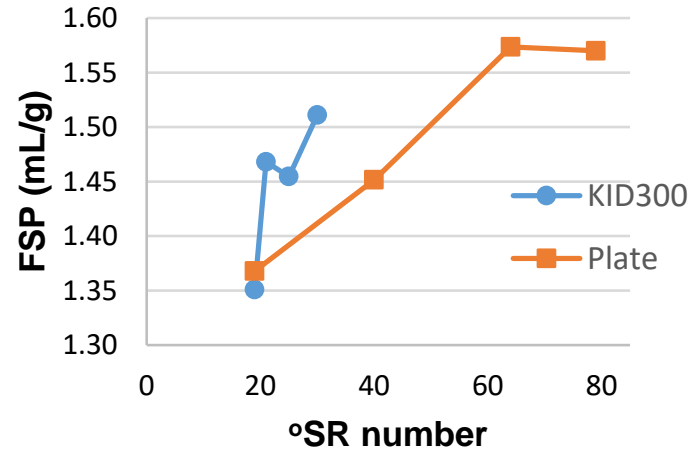

A)

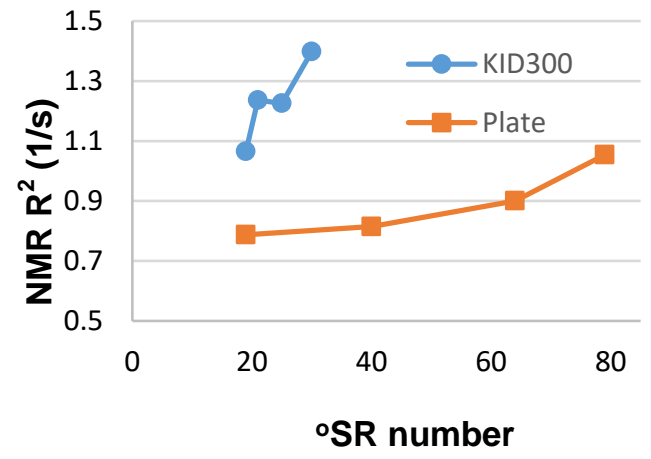

B)

Fig. 6. The effect of the refining method on the fiber saturation point value (a) and the NMR relaxation rate $R_{2}$ value (b)

The correlation of the FSP and NMR relaxation rate $R_{2}$ values was good (Figs. 6a and 6b). In NMR measurements, the consistency of plate-refined pulp was lower compared with the consistency of KID-refined pulp, which explained the difference in levels in the NRM values. This result confirmed that compression refining caused more internal fibrillation compared with plate refining. From the practical point, it was noteworthy that FSP measurement is a laborious method, but low field NMR measurement is rapid and can even be performed continuously online (Nikolskaya and Hiltunen 2019; Nikolskaya et al. 2019; Nikolskaya 2019). In the low field NMR measurement the magnetic field needed for the measurement is not very strong and can be produced with quite small and cheap permanent magnets. This ability could offer the new possibility to continuously monitor and control internal fibrillation or the inner properties of fiber during the pulp and papermaking process.

In Fig. 7, it can be seen that the micropore volume was not affected by the amount of refining using either type of refiner. This result was consistent with early findings by 
Stone and Scallan (1968) and later by Maloney (2000) that demonstrated most pulp refining causes an expansion of the larger pores in the cell wall.

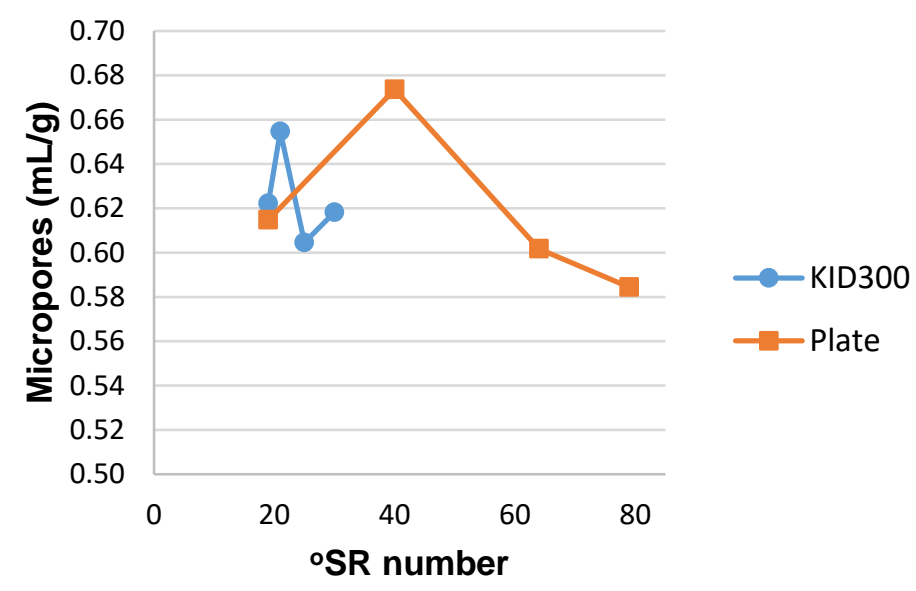

Fig. 7. The effect of the refining method on the amount of micropores

\section{Effect of KID Compression Refining on the Strength Properties}

Although KID refining causes fiber shortening, fines formation, and more damaged fibers, the strength properties remained at the same level as compared with plate refining (Fig. 8). Because of the internal fibrillation, the fibers had greater flexibility, which promoted fiber bonding and fiber network activation, and hence also an increase in density and optical properties such as a decrease in opacity, see Fig. 9.

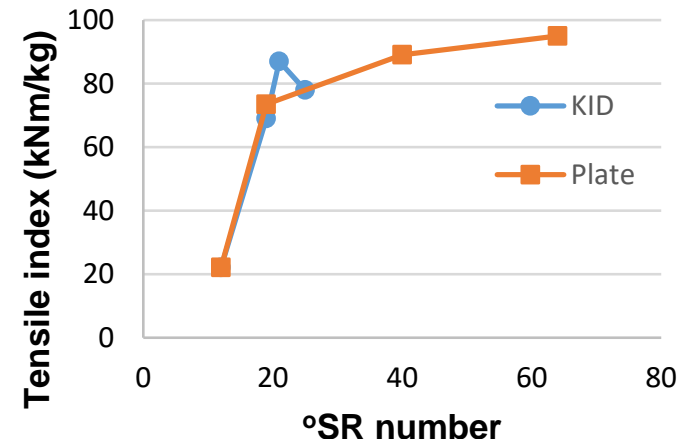

A)

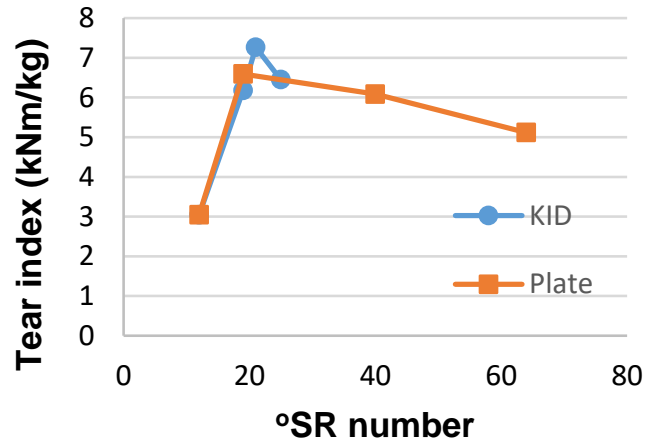

B)

Fig. 8. The effect of the refining method on the tensile index $(A)$ and tear index $(B)$ 


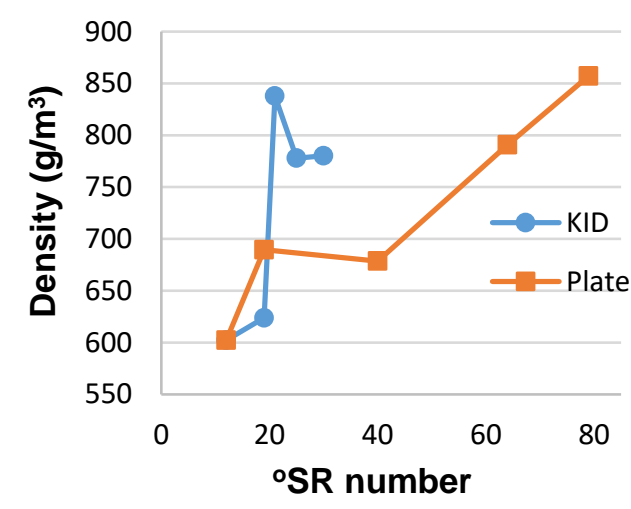

A)

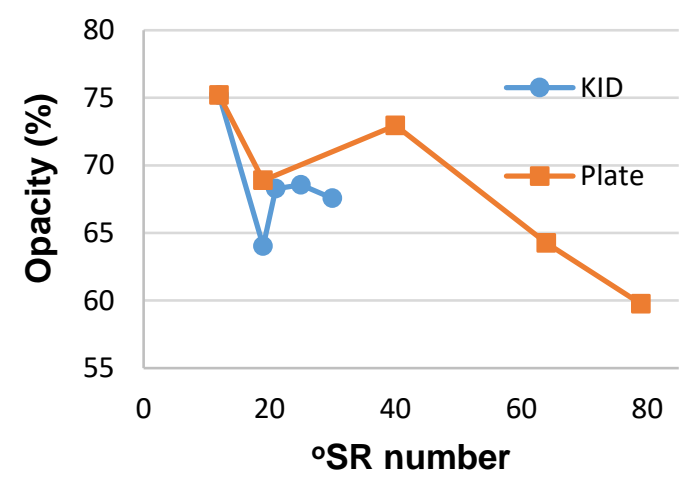

B)

Fig. 9. The effect of the refining method on the density (A) and opacity (B)

\section{Effect of KID Compression Refining on Pulp's Ability to be Beaten}

Because KID refining seemed to cause internal fibrillation and increased fiber flexibility, it was also tested as a pre-treatment for bar refining. Figure 10 demonstrates that although KID treatment itself had a minimal effect on the ${ }^{\circ}$ SR number, it clearly improved the ability of the pulp to be beaten.

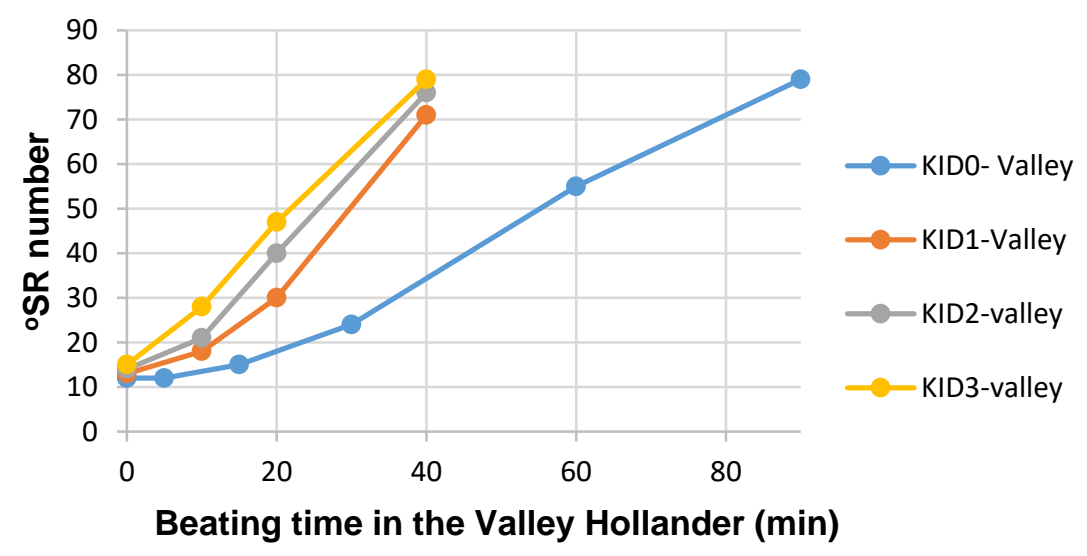

Fig. 10. The effect of KID pre-treatment on the ability of pulp to be beaten (the pulp was treated in the KID refiner from zero to three times before Valley refining)

\section{Energy Consumption}

It was concluded that compression refining could make possible a decrease in energy consumption (Dekker et al. 2007). In KID refining, the net energy consumption in one treatment was approximately $5 \mathrm{kWh} / \mathrm{t}$, and in plate refining approximately $45 \mathrm{kWh} / \mathrm{t}$. On the basis of these numbers it seems that there is much potential to decrease energy consumption using KID refining. At present, the total energy consumption in the KIDrefining treatment was high, at approximately $50 \mathrm{kWh} / \mathrm{t}$. This was because the current structure of the KID refiner was far from optimal in regard to the energy efficiency. In addition, the net energy was determined to be similar to that of the bar refiner (i.e., subtracting no load power from the refining power). It is not clear whether this was the appropriate way to determine the net refining power in KID-compression refining. The thickness of the pulp mat decreased the free gap in the KID refining, and hence the moving 
area of the center part, therefore leading to decreased energy consumption. Therefore, the real net energy consumption was higher than measured with the traditional method used in the bar refining, but it is not known by how much. Because of these issues, it is not possible to evaluate how energy-efficient KID refining could be or become, but it does seem that there is much potential to decrease energy usage in refining.

\section{CONCLUSIONS}

1. KID compression refining is a new refining technology whose refining results differ considerably from traditional bar refining. Its greatest difference when compared with bar refining was that it caused the internal fibrillation of the fiber, which can increase strength properties through increased bonding.

2. In earlier studies, the compressive type of refining has been shown to mainly produce pulp whose fibers are straighter, longer, and contain fewer fines. In KID refining, the results were the opposite. In this study, the compressive impacts on the fibers in the KID refining were so strong that they produced severe damage to the fiber.

3. In KID refining, impact forces can be decreased by changing refining parameters, e.g. increase the width of the refining zone, so there are possibilities to avoid the fiber damages and fines formation in refining and hence improve fiber properties.

4. According to results obtained in this study, by applying compression refining as a pretreatment step before traditional bar refining gives the possibility to optimize different refining action, improve pulp properties, and decrease energy consumption in refining.

5. The fibre saturation point (FSP) and nuclear magnetic resonance (NMR) measurements correlated very well, which indicated that NMR measurements could be used to determine the porosity of the fibers. Although FSP is a laborious laboratory measurement, the low field NMR measurement used in the present study was rapid and can also be used as an online measurement. Its use could give new possibilities for controlling fiber properties in pulp and paper-making processes.

\section{ACKNOWLEDGMENTS}

This work was conducted within the KUUMA and Kuitu-MOD projects financed by The Regional Council of South Savo through EU/ERDF funding and participating companies (ANDRITZ Oy, Laitex Oy, AGS Finland Oy, Vaisala Oy, Pixact Oy, and Boreal Bioref Oy).

\section{REFERENCES CITED}

Dekker, J. C., Bouma, H., and Hooimeijer, A. (2007). "Compression refining: The energy saving breakthrough in papermaking technology," in: Proceedings of the Pulp and Paper 2007 Conference, Espoo, Finland, pp. 27-35

Dunford, J. A., and Wild, P. M. (2002). "Cyclic transverse compression of single woodpulp fibres," Journal of Pulp and Paper Science 28(4), 136-141. 
Eibinger, K., Eichinger, R., and Bauer, W. (2005a). "Property development of virgin and recycled fibres treated with compression refining in a modified PFI mill," in: Proceedings of the PIRA International Refining Conference, Barcelona, Spain, pp. 27-35.

Eibinger, K., Eichinger, R., and Bauer, W. (2005b). "Development of pulp properties by impulse refining - friction-free compression treatment," in: Proceedings of the PTS Paper Symposium, Munich, Germany, pp. 101-111.

Formento, J. C., Maximino, M. G., Adelli, A. M., and Taleb, M. C. (2003). "Selective refining actions on repulped long-fiber kraft paper," TAPPI Journal 2(9), 1-9.

Goosen, D. R., Olson, J. A., and Kerekes, R. (2007). "The role of heterogeneity in compression refining," Journal of Pulp and Paper Science 33(2), 110-114.

Hartman, R. R. (1984). Mechanical Treatment of Pulp Fibres for Property Development, Ph.D. Dissertation, Lawrence University, Appleton, WI, USA.

ISO 5267-1 (1999). "Pulps — Determination of drainability — Part 1: Schopper-Riegler method," International Organization for Standardization, Geneva, Switzerland.

ISO 5269-1 (2005). "Pulps - Preparation of laboratory sheets for physical testing — Part 1: Conventional sheet-former method," International Organization for Standardization, Geneva, Switzerland.

ISO 5270 (2012). "Pulps — Laboratory sheets — Determination of physical properties," International Organization for Standardization, Geneva, Switzerland.

ISO 1924-2 (2008). "Paper and board — Determination of tensile properties - Part 2: Constant rate of elongation method $(20 \mathrm{~mm} / \mathrm{min})$," International Organization for Standardization, Geneva, Switzerland.

ISO 1974 (2012). "Paper - Determination of tearing resistance - Elmendorf method," International Organization for Standardization, Geneva, Switzerland.

ISO 23714 (2014). "Specifies a procedure for the determination of the water retention value (WRV) of all kinds of pulp," International Organization for Standardization, Geneva, Switzerland.

Kibblewhite, R. P. (1974). "Effects of beating on radiata pine kraft paper properties: Effects of beaters," Appita Journal 27(6), 110-118

Maloney, T. (2000). On the Pore Structure and Dewatering Properties of the Pulp Fiber Cell Wall, Ph.D. Dissertation, Helsinki University of Technology, Espoo, Finland.

Murphy, D. C. (1962). "Mechanical factors in beating," Appita Journal 16(1), 16-30.

Nikolskaya, E., and Hiltunen, Y. (2019). "Molecular properties of fatty acid mixtures estimated by online time-domain NMR," Applied Magnetic Resonance 50, 159-170. DOI: 10.1007/s00723-018-1046-6

Nikolskaya, E., Janhunen, P., Haapalainen, M., and Hiltunen, Y. (2019). "Solids content of black liquor measured by online time-domain NMR," Applied Sciences 9(10), Article number 2169. DOI: 10.3390/app9102169

Nikolskaya, E. (2019). "Towards the online characterization of liquid biofuels by timedomain NMR," Publications of the University of Eastern Finland. Dissertations in Forestry and Natural Sciences 354.

SCAN-CM26:99 (1999). "Pulp - Preparation of laboratory sheets for physical testing," Scandinavian Pulp Paper and Board Testing Committee, Espoo, Finland.

SCAN-C 25:76 (1976). "Laboratory beating of chemical pulp with Valley Hollander," Scandinavian Pulp Paper and Board Testing Committee, Espoo, Finland. 
Stone, J. E., and Scallan, A. M. (1968). "A structural model for the cell wall of waterswollen wood pulp fibres based on their accessibility to macromolecules," Cellulose Chemistry and Technology 2(3), 343-358.

Tam Doo, P. A., and Kerekes, R. (1989). "The effect of beating and low-amplitude flexing on pulp fibre flexibility," Journal of Pulp and Paper Science 15(1), J36-J42.

Wang, X., Maloney, T. C., and Paulapuro, H. (2006). "Improving the properties of neverdried chemical pulp by pressing before refining," Nordic Pulp \& Paper Research Journal 21(1), 135-139. DOI: 10.3183/npprj-2006-21-01-p135-139.

Wang, X., and Paulapuro, H. (2005). "Effects of various refining on dry sheet properties of commercial never-dried and dried kraft softwood pulps," in: Proceedings of the 91st PAPTAC Annual Meeting, Book B, Montreal, Canada, pp. 13-21.

Article submitted: April 17, 2020; Peer review completed: September 12, 2020; Revised version received and accepted: September 22, 2020; Published: September 25, 2020.

DOI: 10.15376/biores.15.4.8696-8707 